\title{
Punicalagin, a pomegranate compound, induces apoptosis and autophagy in acute leukemia
}

\author{
Paweena Subkorn ${ }^{1}$, Chosita Norkaew $^{1}$, Kamolchanok Deesrisak ${ }^{1}$, Dalina Tanyong ${ }^{\text {Corresp. } 1}$ \\ ${ }^{1}$ Department of Clinical Microscopy, Faculty of Medical Technology, Mahidol University, Nakhon Pathom, Thailand \\ Corresponding Author: Dalina Tanyong \\ Email address: dalina.itc@mahidol.ac.th
}

Background. Punicalagin is the major phenolic compound found in pomegranate peels. It has several reported medical benefits, including antioxidant, anti-inflammatory, and anticancer properties. The present study investigated the anti-leukemic effects and the molecular mechanism of punicalagin on NB4 and MOLT-4 leukemic cell lines. Methods. Leukemic cells were treated with punicalagin and cell viability was determined using MTS assay. Apoptosis and autophagy were analyzed by flow cytometry using Annexin V-FITC/PI and anti-LC3/FITC antibodies staining, respectively. Apoptotic and autophagic mRNA expression were determined using reverse transcription-quantitative PCR. STITCH bioinformatics tools were used to predict the interaction between punicalagin and its proposed target proteins. Results. Results indicated that punicalagin decreased NB4 and MOLT-4 cell viability in a dose-dependent manner. Punicalagin, in combination with daunorubicin, exhibited synergistic cytotoxic effects. Punicalagin induced apoptosis through the upregulation of caspase-3/-8/-9, Bax and the downregulation of $\mathrm{BCl}-2$ expression. Punicalagin also promoted autophagy via the downregulation of mTOR and the upregulation of ULK1 expression. Cyclooxygenase- 2 and toll-like receptor 4 were found to be involved in punicalagin-induced cell death in punicalagin-targeted protein interactions.Conclusions. These results suggest that punicalagin exerts cytotoxic activities by suppressing proliferation and promoting apoptosis and autophagy by activating the caspase cascade, altering $\mathrm{Bax}$ and $\mathrm{Bcl}-2$, and regulating autophagy via mTOR/ULK1 signaling . 


\section{Punicalagin, a pomegranate compound, induces}

2 apoptosis and autophagy in acute leukemia

3

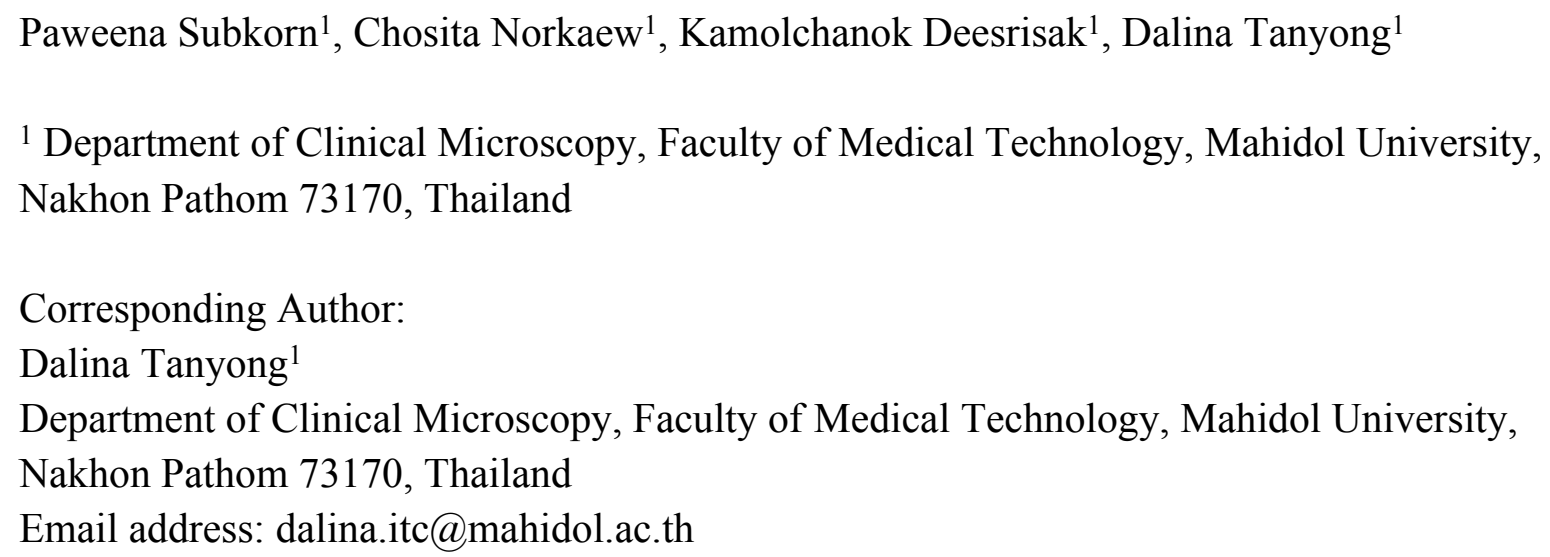

\section{Abstract}

Background. Punicalagin is the major phenolic compound found in pomegranate peels. It has several reported medical benefits, including antioxidant, anti-inflammatory, and anticancer properties. The present study investigated the anti-leukemic effects and the molecular mechanism of punicalagin on NB4 and MOLT-4 leukemic cell lines.

Methods. Leukemic cells were treated with punicalagin and cell viability was determined using MTS assay. Apoptosis and autophagy were analyzed by flow cytometry using Annexin VFITC/PI and anti-LC3/FITC antibodies staining, respectively. Apoptotic and autophagic mRNA expression were determined using reverse transcription-quantitative PCR. STITCH bioinformatics tools were used to predict the interaction between punicalagin and its proposed target proteins.

Results. Results indicated that punicalagin decreased NB4 and MOLT-4 cell viability in a dosedependent manner. Punicalagin, in combination with daunorubicin, exhibited synergistic cytotoxic effects. Punicalagin induced apoptosis through the upregulation of caspase-3/-8/-9, Bax and the downregulation of Bcl-2 expression. Punicalagin also promoted autophagy via the downregulation of mTOR and the upregulation of ULK1 expression. Cyclooxygenase- 2 and tolllike receptor 4 were found to be involved in punicalagin-induced cell death in punicalagintargeted protein interactions.

Conclusions. These results suggest that punicalagin exerts cytotoxic activities by suppressing proliferation and promoting apoptosis and autophagy by activating the caspase cascade, altering Bax and Bcl-2, and regulating autophagy via mTOR/ULK1 signaling.

\section{Introduction}

Leukemia is characterized by an increased production of hematopoietic stem cells in the bone marrow to impairs hematopoiesis (Davis, Viera \& Mea, 2014). There were 60,530 new 
40 leukemia cases and 23,100 deaths in 2020 in the United States (Siegel, Miller \& Jemal, 2020).

41 Treatments for leukemia include chemotherapy, stem cell transplantation, and targeted treatment

42 of the disease (Greaves, 2016). Chemotherapy, which is meant to reduce the number of leukemic

43 cells, has various side effects including nausea, hair loss, and changes in appetite (Ramirez et al.,

44 2009). The relapse of the disease may be associated with conventional chemotherapy (Yilmaz et

45 al., 2019). Therefore, there has been a strong focus on developing alternative medicine using

46 natural compounds and herbs for improving therapeutic efficacy (Hwang et al., 2019; Saedi et

47 al., 2014).

48 Punicalagin (Fig.1) is the major active compound present in pomegranate peel

49 (Khwairakpam et al., 2018). It exhibits antioxidant (Abid et al., 2017), antibacterial (Xu et al.,

50 2017), antiviral (Lin et al., 2013) and anti-inflammatory activities (BenSaad et al., 2017). There

51 is some concern over the bioavailability and concentration of punicalagin and some in vivo

52 bioavailability studies have been conducted (Espín et al., 2007). Ellagic acid is a product of

53 hydrolysis from punicalagin that is metabolized by intestinal microflora with the remaining

54 punicalagin to produce urolithins. The metabolites are then absorbed in intestinal cells and

55 circulated in the blood stream (Espín et al., 2007; Vora, Londhe \& Pandita. 2015). Oral

56 consumption of punicalagin by rats has shown that punicalagin is present in plasma at

57 concentrations of approximately $30 \mu \mathrm{g} / \mathrm{ml}$ (Cerdá et al., 2003).

$58 \quad$ Punicalagin has been reported to have anticancer properties against various cancer cell

59 lines including colon (Larrosa, Tomás-Barberán \& Espín, 2006), ovarian (Tang et al., 2016),

60 prostate (Adaramoye et al., 2017) and lung (Berköz \& Krośniak, 2020) cancer cells due to the

61 inhibition of proliferation and the induction of cell cycle arrest and apoptosis. In vivo,

62 punicalagin demonstrated anti-angiogenic effects by inhibiting blood vessel growth in the

63 chorioallantoic membrane of chickens (Adaramoye et al., 2017). Punicalagin has been shown to

64 possess anti-leukemic activities by suppressing proliferation and promoting apoptosis of HL-60

65 leukemic cells through caspase-3 activation (Chen et al., 2009). Pomegranate juice and peel

66 extracts contain punicalagin, which is responsible for the induction of apoptosis, $\mathrm{S}$ phase cell

67 cycle arrest, and inhibiting proliferation in CCRF-CEM, MOLT-3, HL-60 and THP-1 cells

68 (Dahlawi et al., 2013; Tamborlin et al., 2020).

69

70

71

The induction of cell death through apoptosis, autophagy, and necrosis are key in cancer therapy (Mishra et al., 2018). Punicalagin has been shown to activate the intrinsic apoptosis pathway via the down-regulation of Bcl-XL and the activation of caspase- 9 and caspase- 3 in Caco- 2 colon cells. The activation of the extrinsic pathway via caspase- 8 and caspase- 3 activation in PC-3 prostate cells can also induce apoptosis (Adaramoye et al., 2017; Larrosa, Tomás-Barberán \& Espín, 2006). Punicalagin was also able to induce apoptotic cell death through the inhibition of the $\beta$-catenin and NF- $\kappa$ B signaling pathways in HeLa and ME-180 cells, respectively (Tang et al., 2017; Zhang et al., 2020a). Previous studies have demonstrated that punicalagin can also induce autophagy (Cheng et al., 2016; Wang et al., 2013). The activation of LC3-II conversion, beclin-1 expression, and p62 degradation by punicalagin can 
80

81

82

83

84

85

86

87

88

89

90

91

92

93

94

95

96

97

98

99

100

101

102

103

104

105

106

107

108

109

110

111

112

113

114

115

116

117

118

use resulted in the induction of apoptosis and autophagy in U87MG glioma cells (Wang et al., 2013). However, the mechanism of punicalagin for promoting apoptotic and autophagic cell death in leukemic cells is not known.

We investigated punicalagin's mechanism for inducing apoptosis and autophagy in NB4 and MOLT-4 leukemic cells. We demonstrated that punicalagin inhibited cell proliferation and induced cell death through apoptotic and autophagic mechanisms. Punicalagin treatment resulted in the activation of caspase-3/-8/-9, the alteration of Bax and Bcl-2, and the regulation of mTOR/ULK1 signaling to induce apoptosis and autophagy.

\section{Materials \& Methods}

\section{Leukemic cell culture}

NB4 (acute promyelocytic leukemia cell line) and MOLT-4 (acute lymphocytic leukemia cell line) were purchased from Cell Lines Service (Eppelheim, Germany). Cells were cultured in RPMI-1640 medium supplemented with $1 \%$ antibiotics $(100 \mathrm{U} / \mathrm{ml}$ penicillin and $100 \mu \mathrm{g} / \mathrm{ml}$ streptomycin) and 10\% (v/v) fetal bovine serum (Gibco Life Technologies, Walthem, MA, USA) at $37^{\circ} \mathrm{C}$ with $5 \% \mathrm{CO}_{2}$.

\section{Peripheral blood mononuclear cell (PBMC) isolation}

Human blood samples were collected with the ethical approval of the Mahidol University Central Institutional Review Board (MU-CIRB) (approvals no. MU-CIRB 2019/310.2911) and written informed consent was obtained from all study participants. Peripheral blood mononuclear cells (PBMCs) were isolated through density gradient centrifugation using Lymphoprep ${ }^{\mathrm{TM}}$ (Alere Technology AS, Oslo, Norway). Blood samples were diluted with phosphate buffer saline (PBS) at a 1:1 ratio and the diluted blood was layered over Lymphoprep then centrifuged for $30 \mathrm{~min}$ at 800g. The PBMCs were washed twice with medium after harvesting.

\section{Analysis of cell viability assay by MTS assay}

Leukemic cells $\left(1 \times 10^{4}\right.$ cells/well) were treated with various concentrations of punicalagin $(25$, 50, 75 and $100 \mu \mathrm{g} / \mathrm{ml}$; Sigma-Aldrich, Schnelldorf, Germany). Punicalagin was dissolved in deionized water. We incubated $20 \mu 1$ of Cell Titer 96 Cell Proliferation Assay Solution (Promega Corp., Madison, WI, USA) for 24 and $48 \mathrm{~h}$ before adding the solution to the wells and incubating the samples at $37^{\circ} \mathrm{C}$ for $4 \mathrm{~h}$. The absorbance of the formazan product was measured at $490 \mathrm{~nm}$ using a spectrophotometer with GEN5 ${ }^{\mathrm{TM}}$ analysis software (BioTek Instruments, Inc., Winooski, VT, USA). Cell viability was evaluated using untreated cells as the control and then the halfmaximal inhibitory concentration $\left(\mathrm{IC}_{50}\right)$ was calculated for further experiments.

Leukemic cells $\left(1 \times 10^{4}\right.$ cells/well $)$ and PBMC $\left(1 \times 10^{5}\right.$ cells $/$ well $)$ were treated with $\mathrm{IC}_{50}$ concentration of punicalagin ( 60 and $55 \mu \mathrm{g} / \mathrm{ml}$ for 24 and $48 \mathrm{~h}$, respectively) and $/ \mathrm{or} \mathrm{IC}_{50}$ of daunorubicin ( 0.5 and $0.25 \mu \mathrm{g} / \mathrm{ml}$ for 24 and 48 hours) (TOKU-E, Bellingham, WA, USA), respectively, to determine the synergistic property of punicalagin and daunorubicin. Cell viability was determined using MTS assay. The combination index (CI) was used to analyze the synergistic effect of punicalagin and daunorubicin (Chou \& Talalay, 1984). Synergy, additive 
119 effect and antagonism are indicated by $\mathrm{CI}<1, \mathrm{CI}=1$ and $\mathrm{CI}>1$, respectively. The $\mathrm{CI}$ is

120 calculated using the following equation:

$$
\text { Combination index }(C I)=\frac{(D) 1}{(D \chi) 1}+\frac{(D) 2}{(D \chi) 2}
$$

122

Where (D)1 and (D)2 are concentrations of first compound and second compound that achieve $\mathrm{X} \%$ inhibition in the combination; $(\mathrm{D} \chi) 1$ and $(\mathrm{D} \chi) 2$ are the concentrations of the first compound (alone) and the second compound (alone), respectively, that produce the same effect. Analysis of cell apoptosis by Annexin V-FITC/PI staining Apoptotic cells were quantified using the Annexin V assay kit (BD Biosciences, Palo Alto, CA, USA). The cells $\left(1 \times 10^{5}\right.$ cells/well) were treated with $\mathrm{IC}_{50}$ concentration of punicalagin (55 $\mu \mathrm{g} / \mathrm{ml}$ ) for $48 \mathrm{~h}$ and were then washed twice with PBS. The cells were centrifuged and resuspended in a binding buffer before being stained with Annexin V/FITC and Propidium iodide (PI) for $15 \mathrm{~min}$ in the dark. Data from 10,000 events per sample were collected and apoptotic cells were measured using a FACScantoII flow cytometer (BD Biosciences). Analysis of induction of autophagy by anti-LC3/FITC antibodies staining The Guava ${ }^{\circledR}$ Autophagy LC3 Antibody-based Detection Kit (Luminex Corporation, Austin, USA) was used to determine punicalagin-induced autophagy. The cells were treated with 55 $\mu \mathrm{g} / \mathrm{ml}$ of punicalagin for $48 \mathrm{~h}$ before being incubated with diluted Autophagy Reagent A, which is a lysosomal inhibitor. The cells were centrifuged and resuspended in Autophagy Reagent B. The cells were stained with FITC-conjugated anti-LC3 antibodies. LC3-II mean fluorescence intensity can be used to quantify autophagosomes and this was measured using flow cytometry. Determination of gene expression by reverse transcription-quantitative PCR (RT-qPCR) Leukemic cells were treated with punicalagin at $\mathrm{IC}_{50}$ concentration for $48 \mathrm{~h}$. Total RNA was extracted by Genezol ${ }^{\mathrm{TM}}$ reagent (New England Biolab, Inc., Ipswich, MA, USA) according to the manufacturer's recommendations. First strand cDNA was synthesized by the reverse transcription of $2 \mu \mathrm{g}$ template RNA using the RevertAid first strand cDNA synthesis kit (Themo Scientific, Waltham, MA, USA). cDNA was then amplified by Luna real time PCR master mix (New England Biolan Inc., Ipswich, MA, USA). The primers were designed from literature reviews and their quality was determined by the BLASTN database (Chatupheeraphat et al., 2020; Deesrisak et al., 2021). The primer sequences are shown in Table 1. Real-time PCR was performed with the Bio-Rad thermal cycle CX1000 (Bio-Rad, Inc., Hercules, CA, USA). mRNA expression was normalized to internal control GAPDH. The gene expression was calculated using the $2^{-\Delta \Delta c t}$ method (Livak \& Schmittgen, 2001).

\section{Construction of protein-chemical interaction networks by bioinformatic analysis}

152

The interaction network between punicalagin and its targeted proteins was predicted using the STITCH database. The inputs for analysis were composed of punicalagin, apoptotic proteins (CASP3, CASP8, CASP9, BAX and BCL2) and autophagic proteins (MTOR and ULK1) for Homo sapiens with a medium confidence (0.400). 
157 The experiments were performed in triplicate. Data were expressed as mean \pm standard error of

158

159

160

161

162

163

164

165

166

167

168

169

170

171

172

173

174

175

176

177

178

179

180

181

182

183

184

185

186

187

188

189

190

191

192

193

194

195

196 mean (S.E.M). The results between the two groups were analyzed using the student's $t$-test and comparisons of more than two groups were performed by one-way ANOVA using SPSS (SPSS Inc., Chicago, IL, USA). A statistically significant difference was considered as p-value $<0.05$.

\section{Results}

\section{Effect of punicalagin on the proliferation of leukemic cells}

Leukemic cells (NB4 and MOLT-4) were treated with various concentrations of punicalagin (25, 50,75 and $100 \mu \mathrm{g} / \mathrm{ml}$ ) for 24 and $48 \mathrm{~h}$ to investigate the effects of punicalagin on cell viability. Their viability was examined using the MTS assay. Punicalagin significantly decreased the viability of NB4 and MOLT-4 cells in a dose-dependent manner (Fig. 2A and B). The

comparative results between punicalagin-treated cells and control cells are presented in Table 2 . The $\mathrm{IC}_{50}$ of punicalagin was 57.1 and $53.5 \mu \mathrm{g} / \mathrm{ml}$ in NB4 cells after 24 and $48 \mathrm{~h}$ of treatment as well as 65.7 and $58.9 \mu \mathrm{g} / \mathrm{ml}$ in MOLT- 4 cells after 24 and $48 \mathrm{~h}$ of treatment, respectively. The $\mathrm{IC}_{50}$ value at $48 \mathrm{~h}$ was selected for further experiment as it showed higher cytotoxic effect compared with $24 \mathrm{~h}$. The results suggested that punicalagin inhibited NB4 and MOLT-4 leukemic cells.

\section{Effect of the combination of punicalagin and daunorubicin on leukemic cells}

Cell viability was assessed using the MTS assay to determine the effect of punicalagin combined with a chemotherapeutic drug. NB4 and MOLT-4 cells were first treated with $0.25,0.5,0.75$ and $1 \mu \mathrm{g} / \mathrm{ml}$ of the chemotherapeutic drug, daunorubicin, before being incubated for 24 and $48 \mathrm{~h}$. Daunorubicin decreased the viability of NB4 and MOLT-4 cells in a dose-dependent manner (Fig. 3A and B). The comparisons of cell viability between daunorubicin-treated leukemic cells and control cells are presented in Table 3. NB4 and MOLT-4 were then treated with $\mathrm{IC}_{50}$ of punicalagin, daunorubicin alone, or the combination of both compounds for 24 and $48 \mathrm{~h}$. The combination of punicalagin and daunorubicin significantly decreased cell viability compared with punicalagin or daunorubicin treatment alone (Fig. 4). The effect on PBMCs was also assessed. This combination significantly decreased cell viability of PBMCs but had less effect than NB4 and MOLT-4 leukemic cells. The comparative statistical analyses (p-value) of the combination results were presented in Table 4 and the CI was used to determine the synergistic effect of punicalagin and daunorubicin. The results showed that the CI of NB4 cells after $48 \mathrm{~h}$ of treatment, and the MOLT- 4 cells after 24 and $48 \mathrm{~h}$ of treatments, were $0.80,0.94$ and 0.81 , respectively, which represent a synergistic effect. However, the CI of NB4 cells after $24 \mathrm{~h}$ of treatment was 1.02, which indicates an additive effect. These results suggested that punicalagin enhanced the cytotoxicity of daunorubicin in NB4 and MOLT-4.

\section{Punicalagin induced apoptosis in leukemic cells}

To determine the effect of punicalagin on leukemic cell apoptosis, NB4 and MOLT-4 cells were treated with $\mathrm{IC}_{50}$ concentration of punicalagin. The percentage of apoptotic cells was measured using Annexin V-FITC/PI staining after $48 \mathrm{~h}$ of incubation. Punicalagin significantly increased the total percentage of apoptotic cells in NB4 and MOLT-4 compared with untreated cells as 
197 shown in Fig. 5A-C ( $\mathrm{p}=0.0003$ and 0.0000001 , respectively). The results show punicalagin 198 induced apoptosis in NB4 and MOLT-4 cells.

199 Punicalagin increased the LC3-II level for autophagy induction

200 NB4 and MOLT-4 leukemic cells were treated with $\mathrm{IC}_{50}$ of punicalagin for $48 \mathrm{~h}$ to evaluate the

201

202

203

204

205

206

207

208

209

210

211

212

213

214

215

216

217

218

219

220

221

222

223

224

225

226

227

228

229

230

231

232

233

234

235

236 effect of punicalagin on autophagy. Intracellular autophagosome staining was used to detect autophagic activity. The LC3-II mean fluorescence intensity (MFI), which quantifies autophagosomes, was analyzed by anti-LC3 conjugated FITC antibody staining. The results showed that punicalagin significantly increased LC3-II MFI in NB4 and MOLT-4 compared with the control (Fig. 6A-C) $(\mathrm{p}=0.00002$ and 0.00002 , respectively). The results suggest that punicalagin induced autophagy in NB4 and MOLT-4 cells.

\section{Punicalagin regulated apoptotic and autophagic gene expressions in NB4 and MOLT-4}

\section{leukemic cells}

We examined the alteration of apoptotic mRNA expression, caspase-3, caspase-8, caspase-9, Bax and Bcl-2, and autophagic mRNA expression of mTOR and ULK1 to investigate the mechanism involved in apoptosis and autophagy induction by punicalagin. NB4 and MOLT-4 cells were treated with $\mathrm{IC}_{50}$ of punicalagin for $48 \mathrm{~h}$, which resulted in the mRNA expression of caspase-3, caspase- 8 and caspase- 9 to be significantly upregulated $(p=0.023,0.00001$ and 0.019 for NB4; $p=0.022,0.026$ and 0.01 for MOLT-4, respectively). These results indicate caspase activation as shown in Fig. 7A. The B-cell lymphoma 2 (Bcl-2) family is an apoptosis regulator that consists of both pro-apoptotic genes, such as Bax, and anti-apoptotic genes, such as Bcl-2. The results showed that punicalagin upregulated the expression of $\operatorname{Bax}(p=0.001$ for NB4; $p=$ 0.00009 for MOLT-4) and downregulated the expression of Bcl-2 ( $p=0.023$ and 0.036 for NB4 and MOLT-4, respectively) as shown in Fig. 7B. Moreover, mTOR mRNA expression was significantly decreased ( $\mathrm{p}=0.002$ and 0.002 for NB4 and MOLT-4 cells, respectively) whereas ULK1 mRNA expression was significantly increased $(p=0.036$ for NB4; $p=0.045$ for MOLT4) in punicalagin-treated cells (Fig. 7C).

\section{Prediction of protein-chemical interactions}

Protein-chemical interactions were obtained from STITCH databases and the results showed the interaction between punicalagin and the related proteins. Analysis revealed that punicalagin was related to proteins which play a role in induction of apoptosis (CASP3, CASP8, CASP9, BAX, BCL2, BCL2L11 and APAF1) and mTOR signaling in autophagy regulation (MTOR, ULK1, RPTOR, RICTOR, RPS6KB1, MLST8, EIF4EBP1, FKBP1A and MAPKAP1) via cyclooxygenase-2 (PTGS2) and toll-like receptor 4 (TLR4) (Fig. 8). We determined that caspase-3/-8/-9, Bax, Bcl-2, and mTOR and ULK1 play roles in apoptotic and autophagic signaling pathways in punicalagin treatment.

\section{Discussion}

Punicalagin is a major polyphenolic compound found in pomegranate. It reportedly has several biological properties, including antioxidant (Abid et al., 2017), anti-inflammatory (BenSaad et al.. 2017) and anticancer properties (Adaramoye et al., 2017; Berköz \& Krośniak, 
237 2020; Larrosa, Tomás-Barberán \& Espín, 2006; Tang et al., 2016). We studied the anti-leukemic 238 effects of punicalagin and the mechanism underlying the induction of apoptosis and autophagy 239 on NB4 and MOLT-4 leukemic cells. Punicalagin suppressed the proliferation of NB4 and 240 MOLT-4 cells. The cytotoxic effect of punicalagin exhibited a nonsignificant increase on NB4

241

242

243

244

245

246

247

248

249

250

251

252

253

254

255

256

257

258

259

260

261

262

263

264

265

266

267

268

269

270

271

272

273

274

275

276 compared with MOLT-4 cells. Punicalagin was also found to exhibit a synergistic effect with daunorubicin in this study. The combination improved the cytotoxic effect on leukemic cells with low cytotoxicity on healthy PBMC. Punicalagin was also reported to exert a low antiproliferative effect on PBMC compared with HL-60 leukemic cells (Chen et al., 2009). Natural products in combination with chemotherapy drugs have been shown to reduce adverse effects and improve the therapeutic effects of chemotherapy drugs in cancer treatment (Zhang et al., 2020b). Punicalagin was shown to enhance the cytotoxicity of daunorubicin, suggesting that punicalagin may be used in combination with conventional chemotherapy drugs. The mechanism of actions of punicalagin and daunorubicin are still unclear. Daunorubicin is able to intercalate DNA strands to inhibit DNA and RNA synthesis and the topoisomerase II enzyme, and produce reactive oxygen species (ROS) leading to DNA damage and apoptosis (Al-Aamri et al., 2019). It is possible that punicalagin's mechanism in apoptosis induction may function via the caspase pathway and autophagy via the mTOR/ULK1 pathway. The results of the combined treatment may be related to the similar caspase pathway. Further studies on the side effects of combining punicalagin and daunorubicin treatment are required for determining its role in the inhibition of cell viability.

Apoptosis or type I programmed cell death is characterized by caspase-dependent proteolytic activation, membrane blebbing, and DNA fragmentation. The activation of apoptosis eliminates cancer cells and it is the therapeutic approach for the development of anti-cancer drugs (Carneiro \& El-Deiry, 2020). The activation of caspase-8 and caspase-9 plays critical roles in the extrinsic and intrinsic apoptotic pathway, respectively. The active caspase- 8 or caspase- 9 further activate caspase-3, leading to apoptosis (Mishra et al., 2018). Our results revealed that punicalagin increased the mRNA expression of caspase-3, caspase- 8 and caspase-9. Moreover, the Bcl-2 family proteins are mitochondrial apoptotic regulators which can be either proapoptotic proteins, such as Bax, or anti-apoptotic proteins, such as Bcl-2 (Mishra et al., 2018). Punicalagin was shown to upregulate Bax mRNA expression and downregulate Bcl-2 mRNA expression in this study. Therefore, our results indicated that punicalagin induced apoptosis via intrinsic and extrinsic apoptotic pathways by activating caspase-3/-8-9 and altering Bax/Bcl-2 in NB4 and MOLT-4 cells. Punicalagin-induced apoptosis has been demonstrated in Caco-2 colon, PC-3 prostate and HeLa cervical cancer cells (Adaramoye et al., 2017; Larrosa, Tomás-Barberán \& Espín, 2006; Zhang et al., 2020a). The induction of apoptosis by natural products has been reported in leukemic cell lines (Cetintas et al., 2014; Debnath et al., 2019). Capsaicin is a component of red chili peppers that has been shown to upregulate the expression of caspase gene family members, activate caspase- 3 activity and downregulate the expression of Bcl-2 to induce apoptosis in CCRF-CEM cells (Cetintas et al., 2014). Bromelain, a pineapple enzyme, in combination with peroxidase, suppressed K562 cell proliferation and promoted the intrinsic 
277 pathway of apoptosis through the alteration of the mitochondrial membrane and the regulation of 278 the expression of apoptosis-related proteins, including Bax, Bcl-2, caspase-3 and cytochrome c 279 (Debnath et al., 2019).

280 Autophagy plays an important role in tumor suppression through the elimination of 281 damaged organelles or proteins, the inhibition of the survival of cancer cells, and the induction of 282 cell death. Several proteins, including AMP-activated protein kinase (AMPK), mammalian target 283 of rapamycin (mTOR), Unc-51-like autophagy-activating kinase (ULK), autophagy-related 284 protein (ATG) and beclin-1, are involved in the regulation of autophagy (Yun \& Lee, 2018). 285 Previous studies demonstrated that punicalagin exhibits anticancer activities via the induction of 286 autophagy, which plays a role in cancer cell death (Cheng et al., 2016; Wang et al., 2013). The 287 upregulation of mTOR inhibits autophagy resulting in the stimulation of cancer growth and 288 progression. Thus, mTOR inhibitors have been developed for cancer therapy (Hua et al., 2019). 289 290 291

292

293 The inhibition of mTOR promotes ULK1 activation which is required for autophagy induction (Kim et al., 2011). Resveratrol, a polyphenolic compound found in berries and grapes, induces autophagy by inhibiting mTOR and activating ULK1 activity (Park et al., 2016). Results from the present study have shown that punicalagin induced autophagy through the increased expression of LC3-II as well as the downregulation of mTOR expression and the upregulation of ULK1 expression. Alterations in gene expression may correlate with protein levels. However, gene expression does not prove the existence of the proteins. The effects of punicalagin treatment on protein expression have been investigated (Ganesan et al., 2020; Wang et al., 2013). Immunoblot analysis demonstrated that the expression of the $\mathrm{Bcl}-2$ protein was decreased while the expression of cleaved caspase-9 and cleaved poly (ADP-ribose) polymerase (PARP) were increased by punicalagin treatment. The increased expression of LC3-II and the phosphorylation of AMPK and p27 were associated with autophagy induction (Wang et al., 2013). Furthermore, the expression of 35 different apoptosis/autophagy-related proteins have been studied using proteome profiling analysis. The results revealed that the altered protein expression of heat shock protein (HSP) 27, HSP 60, catalase, tumor necrosis factor receptor 1/tumor necrosis factor receptor superfamily member 1A (TNFRI/ TNFRSF1A), p53, Bax, Bcl-2, Smac/Diablo, HSP 70, p21 and p27 play roles in the activation or inhibition of apoptosis and/or autophagy in punicalagin-treated HCT 116 cells (Ganesan et al., 2020).

The interaction between punicalagin and the target proteins was constructed using the STITCH bioinformatics tool for an increased understanding the molecular mechanism of apoptosis and autophagy in response to punicalagin. PTGS2 (Cyclooxygenase-2; COX-2) and toll-like receptor 4 (TLR4) were involved in the punicalagin-related molecules interaction network. COX-2, a proinflammatory enzyme required for prostaglandins synthesis, is overexpressed in inflammatory diseases and cancer. COX-2 increases mutated cell proliferation and modulates programmed cell death to promote cancer progression in several cancer models (Liu, Qu \& Yan, 2015; Sobolewski et al., 2010). COX-2 is able to prevent apoptosis by increasing the expression of surviving Mcl-2 and Bcl-2 anti-apoptotic proteins by decreasing caspase-3 expression (Goradel et al., 2019). The suppression of COX-2 is associated with 
317 autophagy leading to neuronal cell death (Niranjan, Mishra \& Thakur, 2018). Several studies

318 have reported natural compounds for cancer chemoprevention that have the potential to suppress

319 COX-2 expression (Cerella et al., 2010). For example, curcumin, a flavonoid from Curcuma

320 longa, inhibits COX-2 and its downstream genes resulting in the induction of apoptosis through

321 the regulation of AMP-activated protein kinase (AMPK) in MCF-7 breast cancer cells and

322 HT-29 colon cancer cells (Mortezaee et al., 2019). Moreover, COX-2 protein expression is

323

324

325

326

327

328

329

330

331

332

333

334

335

336

337

338

339

340

341

342

343

344

345

346

347

348

349

350

351

352

353 inhibited by punicalagin in HT-29 colon cancer cells and mice brain (Adams et al., 2006; Kim et al., 2017). Toll-like receptor 4 (TLR4) transmembrane receptors play key roles in the inflammatory immune response (Hao et al., 2018) and were present in the punicalagin-related proteins network. TLR4 expression reportedly increased in various tumor cells including those involved in the development of non-small cell lung cancer (Wang et al., 2017), breast cancer (Yang et al., 2014) and hepatocarcinoma (Gong et al., 2013). STITCH is a useful resource that incorporates data from metabolic pathways, crystal structures, binding experiments and drugtarget relationships (Kuhn et al., 2008). It provides generalized analysis for the overview of the interaction between the chemical and its targets and is not a cell type-specific tool. Our results indicate that the protein interactions between punicalagin and its targets in NB4 and MOLT-4 cells should be considered in future research.

\section{Conclusions}

Our study revealed that punicalagin exerted anti-leukemic effects by suppressing cell proliferation and promoting apoptotic and autophagic cell death by regulating caspase, Bax/Bcl-2 and the mTOR/ULK1 signaling pathway. The findings of this study may assist in the creation of complementary and alternative treatments in the future.

\section{References}

Abid M, Yaich H, Cheikhrouhou S, Khemakhem I, Bouaziz M, Attia H, Ayadi MA. 2017.

Antioxidant properties and phenolic profile characterization by LC-MS/MS of selected Tunisian pomegranate peels. Journal of Food Science and Technology 54:2890-2901.

Adams LS, Seeram NP, Aggarwal BB, Takada Y, Sand D, Heber D. 2006. Pomegranate juice, total pomegranate ellagitannins, and punicalagin suppress inflammatory cell signaling in colon cancer cells. Journal of Agricultural and Food Chemistry 54(3):980-985.

Adaramoye O, Erguen B, Nitzsche B, Höpfner M, Jung K, Rabien A. 2017. Punicalagin, a polyphenol from pomegranate fruit, induces growth inhibition and apoptosis in human PC-3 and LNCaP cells. Chemico-Biological Interactions 274:100-106.

Al-Aamri HM, Ku H, Irving HR, Tucci J, Meehan-Andrews T, Bradley C. 2019. Time dependent response of daunorubicin on cytotoxicity, cell cycle and DNA repair in acute lymphoblastic leukaemia. BMC Cancer 19(1):179. 
354 BenSaad LA, Kim KH, Quah CC, Kim WR, Shahimi M. 2017. Anti-inflammatory potential of 355 ellagic acid, gallic acid and punicalagin A\&B isolated from Punica granatum. BMC complementary and alternative medicine 17(1):47.

357

358

359

360

361

362 363

364 365

366

367

368

369

370

371

372

373

374

375

376

377

378

379

380

381

382

383 384

Berköz M, Krośniak M. 2020. Punicalagin induces apoptosis in A549 cell line through mitochondria-mediated pathway. General physiology and biophysics 39(6), 557-567.

Bozok Cetintas V, Tezcanli Kaymaz B, Aktug H, Oltulu F, Taskiran D. 2014. Capsaicin induced apoptosis and gene expression dysregulation of human acute lymphoblastic leukemia CCRFCEM cells. Journal of B.U.ON.: official journal of the Balkan Union of Oncology 19(1):183-190.

Carneiro BA, El-Deiry WS. 2020. Targeting apoptosis in cancer therapy. Nature Reviews Clinical Oncology 17(7):395-417.

Cerdá B, Llorach R, Cerón JJ, Espín JC, Tomás-Barberán FA. 2003. Evaluation of the bioavailability and metabolism in the rat of punicalagin, an antioxidant polyphenol from pomegranate juice. European Journal of Nutrition 42(1):18-28.

Cerella C, Sobolewski C, Dicato M, Diederich M. 2010. Targeting COX-2 expression by natural compounds: A promising alternative strategy to synthetic COX-2 inhibitors for cancer chemoprevention and therapy. Biochemical Pharmacology 80(12):1801-1815.

Chatupheeraphat C, Nantasenamat C, Deesrisak K, Roytrakul S, Anurathapan U, Tanyong D. 2020. Bioinformatics and experimental studies of anti-leukemic activity from 6-gingerol demonstrate its role in p53 mediated apoptosis pathway. EXCLI journal 19:582-595.

Chen LG, Huang WT, Lee LT, Wang CC. 2009. Ellagitannins from Terminalia calamansanai induced apoptosis in HL-60 cells. Toxicology in Vitro 23(4):603-609.

Cheng X, Gao Y, Yao X, Yu H, Bao J, Guan H, Sun Y, Zhang L. 2016. Punicalagin induces apoptosis-independent autophagic cell death in human papillary thyroid carcinoma BCPAP cells. RSC Advances 6:68485-68493.

Chou TC, Talalay P. 1984. Quantitative analysis of dose-effect relationships: the combined effects of multiple drugs or enzyme inhibitors. Advances in enzyme regulation 22:27-55.

Dahlawi H, Jordan-Mahy N, Clench M, McDougall GJ, Maitre CL. 2013. Polyphenols are responsible for the proapoptotic properties of pomegranate juice on leukemia cell lines. Food science \& nutrition 1(2):196-208.

Davis AS, Viera AJ, Mea MD. 2014. Leukemia: an overview for primary care. American family physician 89(9):731-738. 
385 Debnath R, Chatterjee N, Das S, Mishra S, Bose D, Banerjee S, Das S, Saha KD, Ghosh D, Maiti 386 D. 2019. Bromelain with peroxidase from pineapple are more potent to target leukemia growth 387 inhibition - A comparison with only bromelain. Toxicology in Vitro 55:24-32.

388 Deesrisak K, Chatupheeraphat C, Roytrakul S, Anurathapan U, Tanyong D. 2021. Autophagy 389 and apoptosis induction by sesamin in MOLT-4 and NB4 leukemia cells. Oncology letters 390 21(1):32.

391 Espín JC, González-Barrio R, Cerdá B, López-Bote C, Rey AI, Tomás-Barberán FA. 2007. 392 Iberian pig as a model to clarify obscure points in the bioavailability and metabolism of 393 ellagitannins in humans. Journal of Agricultural and Food Chemistry 55(25):10476-10485.

394 Ganesan T, Sinniah A, Chik Z, Alshawsh MA. 2020. Punicalagin regulates apoptosis-autophagy 395 switch via modulation of annexin A1 in colorectal cancer. Nutrients 12(8):2430.

396 Gong W, Wang ZY, Chen GX, Liu YQ, Gu XY, Liu WW. 2013. Invasion potential of H22

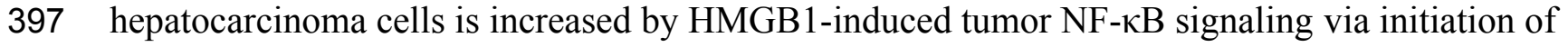
398 HSP70. Oncology reports 30(3):1249-1256.

399 Greaves M. 2016. Leukaemia 'firsts' in cancer research and treatment. Nature Reviews Cancer 400 16(3):163-172.

401 Hao B, Chen Z, Bi B, Yu M, Yao S, Feng Y, Yu Y, Pan L, Di D, Luo G, Zhang X. 2018. Role of 402 TLR4 as a prognostic factor for survival in various cancers: a meta-analysis. Oncotarget 403 9(16):13088-13099.

404 Hashemi Goradel N, Najafi M, Salehi E, Farhood B, Mortezaee K. 2019. Cyclooxygenase-2 in 405 cancer: A review. Journal of Cellular Physiology 234(5):5683-5699.

406 Hua H, Kong Q, Zhang H, Wang J, Luo T, Jiang Y. 2019. Targeting mTOR for cancer therapy. 407 Journal of Hematology \& Oncology 12(1):71.

408 Hwang D, Kim M, Park H, Jeong MI, Jung W, Kim B. 2019. Natural products and acute myeloid 409 leukemia: A review highlighting mechanisms of action. Nutrients 11(5):1010.

410 Khwairakpam AD, Bordoloi D, Thakur KK, Monisha J, Arfuso F, Sethi G, Mishra S, Kumar AP, 411 Kunnumakkara AB. 2018. Possible use of Punica granatum (Pomegranate) in cancer therapy. 412 Pharmacological Research 133:53-64.

413 Kim J, Kundu M, Viollet B, Guan KL. 2011. AMPK and mTOR regulate autophagy through 414 direct phosphorylation of Ulk1. Nature cell biology 13:132-141. 
415 Kim YE, Hwang CJ, Lee HP, Kim CS, Son DJ, Ham YW, Hellström M, Han SB, Kim HS, Park 416 EK, Hong JT. 2017. Inhibitory effect of punicalagin on lipopolysaccharide-induced 417 neuroinflammation, oxidative stress and memory impairment via inhibition of nuclear factor418 kappaB. Neuropharmacology 117:21-32.

419 Kuhn M, von Mering C, Campillos M, Jensen LJ, Bork P. 2008. STITCH: interaction networks 420 of chemicals and proteins. Nucleic acids research 36:684-688.

421 Larrosa M, Tomás-Barberán FA, Espín JC. 2006. The dietary hydrolysable tannin punicalagin 422 releases ellagic acid that induces apoptosis in human colon adenocarcinoma Caco-2 cells by 423 using the mitochondrial pathway. The Journal of Nutritional Biochemistry 17(9):611-625.

424 Lin LT, Chen TY, Lin SC, Chung CY, Lin TC, Wang GH, Anderson R, Lin CC, Richardson CD. 425 2013. Broad-spectrum antiviral activity of chebulagic acid and punicalagin against viruses that 426 use glycosaminoglycans for entry. BMC microbiology 13:187-187.

427 Liu B, Qu L, Yan S. 2015. Cyclooxygenase-2 promotes tumor growth and suppresses tumor 428 immunity. Cancer cell international 15:106.

429 Livak KJ, Schmittgen TD. 2001. Analysis of relative gene expression data using real-time 430 quantitative PCR and the 2- $\Delta \Delta \mathrm{CT}$ method. Methods 25(4):402-408.

431 Mishra AP, Salehi B, Sharifi-Rad M, Pezzani R, Kobarfard F, Sharifi-Rad J, Nigam M. 2018. 432 Programmed cell death, from a cancer perspective: An overview. Molecular Diagnosis \& 433 Therapy 22(3):281-295.

434 Mortezaee K, Salehi E, Mirtavoos-mahyari H, Motevaseli E, Najafi M, Farhood B, Rosengren 435 RJ, Sahebkar A. 2019. Mechanisms of apoptosis modulation by curcumin: Implications for 436 cancer therapy. Journal of Cellular Physiology 234(8):12537-12550.

437 Niranjan R, Mishra KP, Thakur AK. 2018. Inhibition of cyclooxygenase-2 (COX-2) initiates 438 autophagy and potentiates MPTP-induced autophagic cell death of human neuroblastoma cells, 439 SH-SY5Y: An inside in the pathology of Parkinson's disease. Molecular Neurobiology 440 55(10):8038-8050.

441 Park D, Jeong H, Lee MN, Koh A, Kwon O, Yang YR, Noh J, Suh PG, Park H, Ryu SH. 2016. 442 Resveratrol induces autophagy by directly inhibiting mTOR through ATP competition. Scientific 443 Reports 6:21772.

444 Ramirez LY, Huestis SE, Yap TY, Zyzanski S, Drotar D, Kodish E. 2009. Potential 445 chemotherapy side effects: what do oncologists tell parents? Pediatric blood \& cancer 446 52(4):497-502. 
447 Saedi TA, Md Noor S, Ismail P, Othman F. 2014. The effects of herbs and fruits on leukaemia.

448 Evidence-Based Complementary and Alternative Medicine 2014:494136.

449 Siegel RL, Miller KD, Jemal A. 2020. Cancer statistics, 2020. CA: A Cancer Journal for 450 Clinicians 70:7-30.

451 Sobolewski C, Cerella C, Dicato M, Ghibelli L, Diederich M. 2010. The role of cyclooxygenase4522 in cell proliferation and cell death in human malignancies. International journal of cell biology $453 \quad 2010: 215158$.

454 Tamborlin L, Sumere BR, de Souza MC, Pestana NF, Aguiar AC, Eberlin MN, Simabuco FM, 455 Rostagno MA, Luchessi AD. 2020. Characterization of pomegranate peel extracts obtained using 456 different solvents and their effects on cell cycle and apoptosis in leukemia cells. Food science \& 457 nutrition 8:5483-5496.

458 Tang JM, Min J, Li BS, Hong SS, Liu C, Hu M, Li Y, Yang J, Hong L. 2016. Therapeutic effects 459 of punicalagin against ovarian carcinoma cells in association with $\beta$-catenin signaling inhibition. 460 International Journal of Gynecologic Cancer 26(9):1557.

461 Tang J, Li B, Hong S, Liu C, Min J, Hu M, Li Y, Liu Y, Hong L. 2017. Punicalagin suppresses 462 the proliferation and invasion of cervical cancer cells through inhibition of the $\beta$-catenin 463 pathway. Molecular medicine reports 16(2):1439-1444.

464 Vora A, Londhe V, Pandita N. 2015. Herbosomes enhance the in vivo antioxidant activity and 465 bioavailability of punicalagins from standardized pomegranate extract. Journal of Functional 466 Foods 12:540-548.

467 Wang K, Wang J, Wei F, Zhao N, Yang F, Ren X. 2017. Expression of TLR4 in non-small cell 468 lung cancer is associated with PD-L1 and poor prognosis in patients receiving pulmonectomy. 469 Frontiers in immunology 8:456.

470 Wang SG, Huang MH, Li JH, Lai FI, Lee HM, Hsu YN. 2013. Punicalagin induces apoptotic 471 and autophagic cell death in human U87MG glioma cells. Acta pharmacologica Sinica 472 34(11):1411-1419.

473 Xu Y, Shi C, Wu Q, Zheng Z, Liu P, Li G, Peng X, Xia X. 2017. Antimicrobial activity of 474 punicalagin against Staphylococcus aureus and its effect on biofilm formation. Foodborne 475 Pathogens and Disease 14(5):282-287.

476 Yang H, Wang B, Wang T, Xu L, He C, Wen H, Yan J, Su H, Zhu X. 2014. Toll-like receptor 4 477 prompts human breast cancer cells invasiveness via lipopolysaccharide stimulation and is 478 overexpressed in patients with lymph node metastasis. PloS one 9(10):109980. 
479 Yilmaz M, Wang F, Loghavi S, Bueso-Ramos C, Gumbs C, Little L, Song X, Zhang J, Kadia T, 480 Borthakur G, Jabbour E, Pemmaraju N, Short N, Garcia-Manero G, Estrov Z, Kantarjian H, 481 Futreal A, Takahashi K, Ravandi F. 2019. Late relapse in acute myeloid leukemia (AML): clonal 482 evolution or therapy-related leukemia? Blood cancer journal 9(2):7.

483 Yun CW, Lee SH. 2018. The roles of autophagy in cancer. International journal of molecular 484 sciences 19(11):3466.

485 Zhang L, Chinnathambi A, Alharbi SA, Veeraraghavan VP, Mohan SK, Zhang G. 2020a. 486 Punicalagin promotes the apoptosis in human cervical cancer (ME-180) cells through 487 mitochondrial pathway and by inhibiting the NF-kB signaling pathway. Saudi Journal of 488 Biological Sciences 27(4):1100-1106.

489 Zhang Y, Li H, Zhang J, Zhao C, Lu S, Qiao J, Han M. 2020b. The combinatory effects of 490 natural products and chemotherapy drugs and their mechanisms in breast cancer treatment. 491 Phytochemistry Reviews 19:1179-1197. 
Figure 1

Chemical structure of punicalagin. 


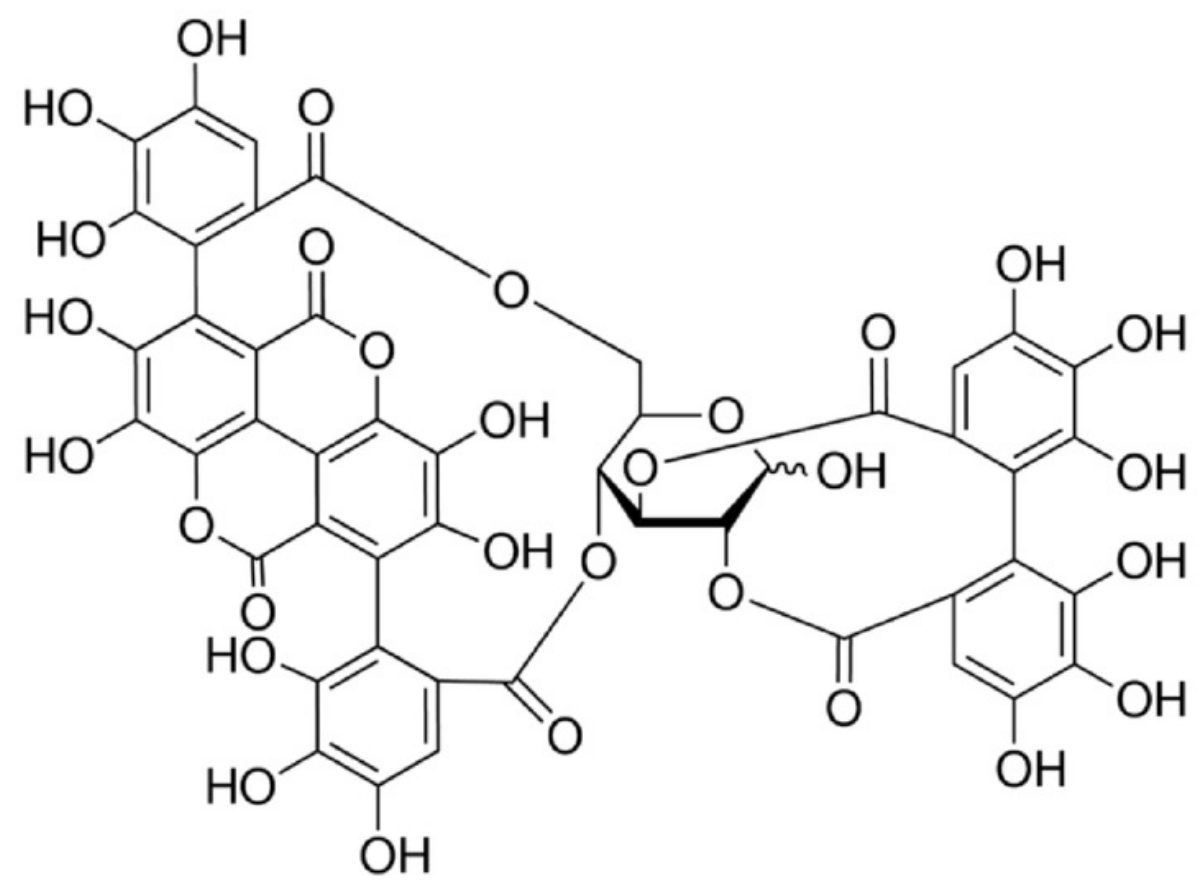


Figure 2

Punicalagin inhibits the cell viability of leukemic cells.

(A) NB4 and (B) MOLT-4 leukemic cells were treated with various concentrations of punicalagin for 24 and $48 \mathrm{~h}$. Cell viability was measured using MTS assay. *p $<0.05$ was considered to be a statistically significant difference from the control. 
A

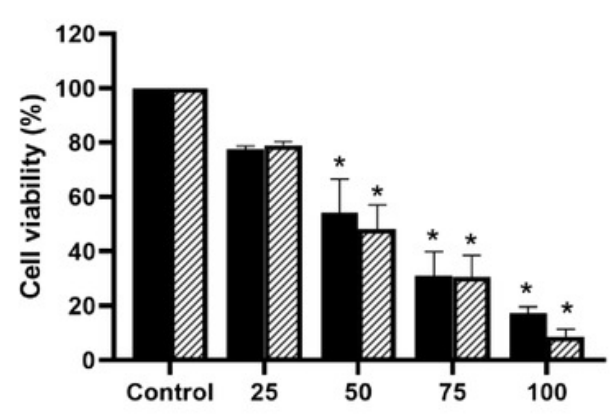

Punicalagin concentration $(\mu \mathrm{g} / \mathrm{ml})$
B

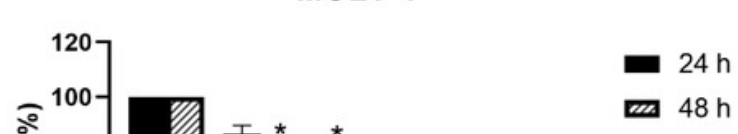


Figure 3

Effect of daunorubicin on cell viability in leukemic cell lines.

(A) NB4 and (B) MOLT-4 leukemic cells were treated with various concentrations of daunorubicin for 24 and $48 \mathrm{~h}$. Cell viability was determined by MTS assay. *p $<0.05$ was considered to be a statistically significant difference from the control. 

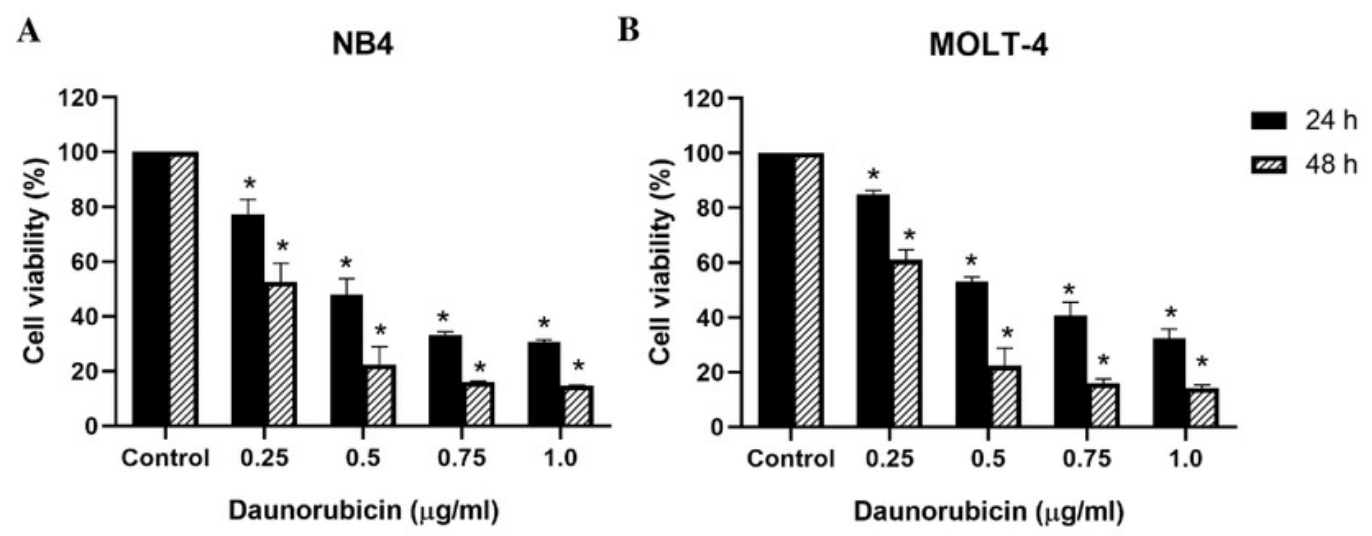


\section{Figure 4}

The synergistic effect of punicalagin and daunorubicin.

NB4, MOLT-4, and peripheral blood mononuclear cells (PBMC) were treated with $\mathrm{IC}_{50}$ of punicalagin with or without daunorubicin for (A) $24 \mathrm{~h}$ and (B) $48 \mathrm{~h}$. Cell viability was measured using MTS assay. ${ }^{*} p<0.05$ was considered to be a statistically significant difference between the punicalagin treatment alone and daunorubicin treatment alone. 
A

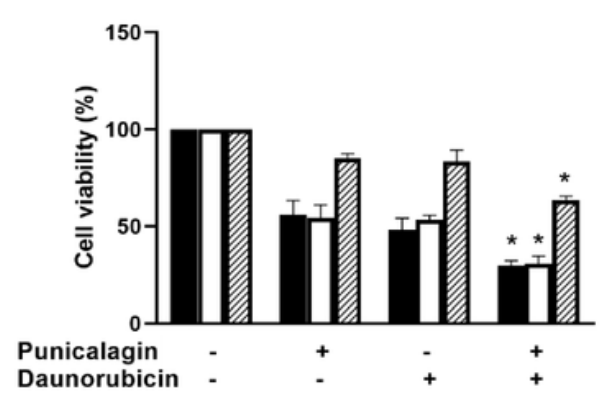

B

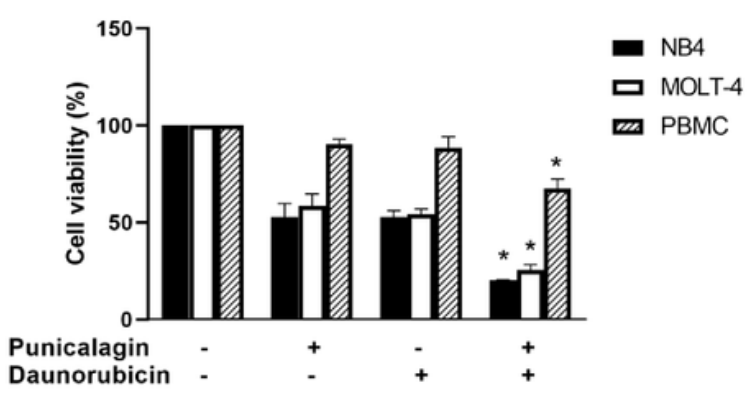




\section{Figure 5}

Effect of punicalagin on early and late apoptotic cells.

NB4 and MOLT-4 cells were treated with $\mathrm{IC}_{50}$ of punicalagin for $48 \mathrm{~h}$ and the percentage of apoptotic cells was analyzed using flow cytometry. Scatter plots of Annexin V-FITC/PI stained (A) NB4 and (B) MOLT-4 cells were treated with or without punicalagin. (C) Quantitative results of early and late apoptotic cells. Data were expressed as the mean \pm SEM of three independent experiments. ${ }^{*} p<0.05$ was considered to be a statistically significant difference from the control group. 
A

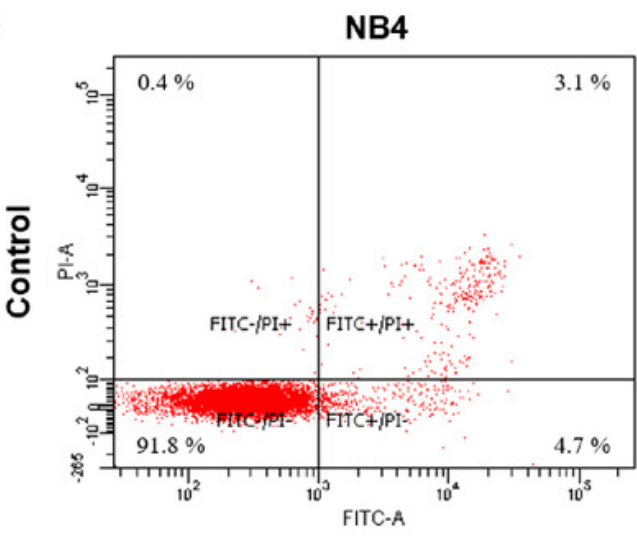

NB4

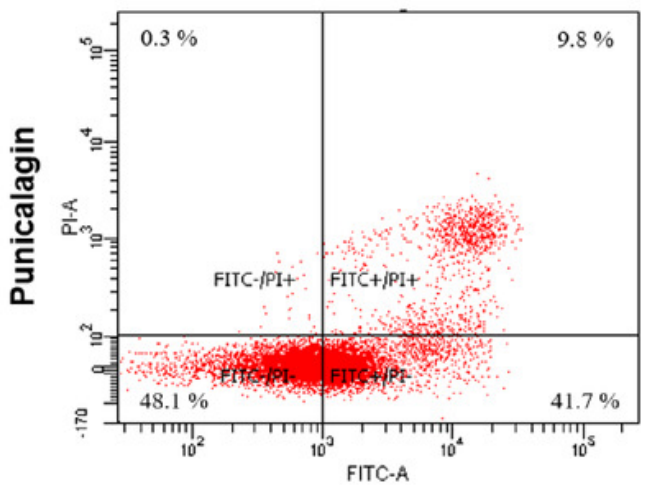

C

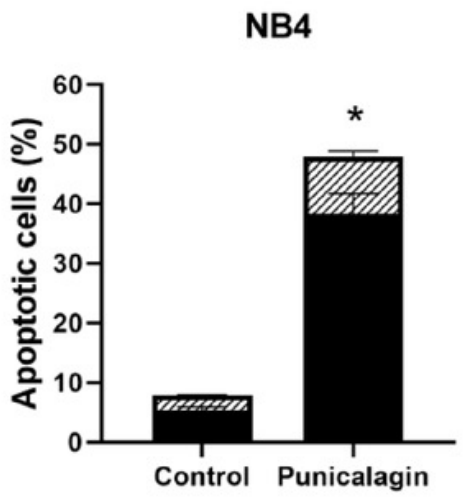

B

MOLT-4

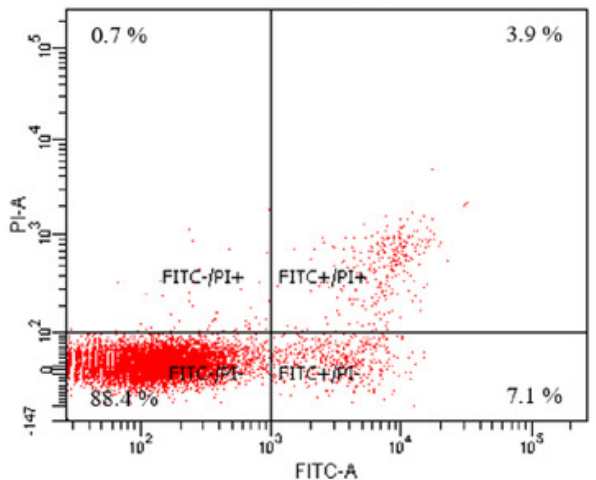

MOLT-4

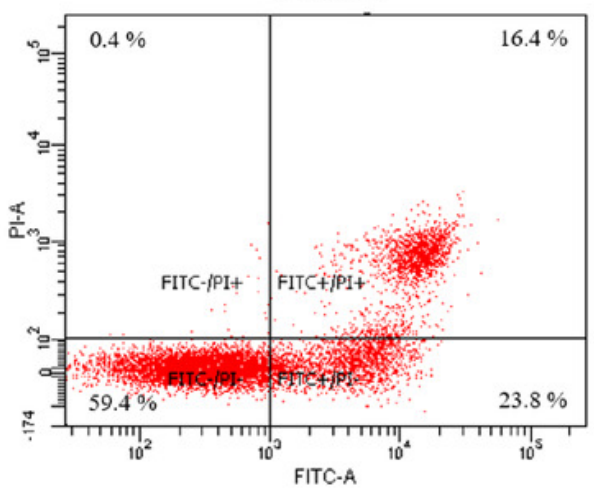

MOLT-4

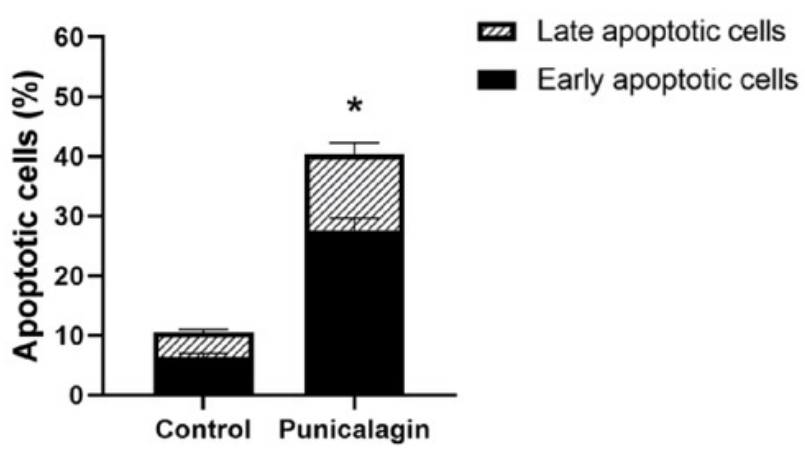


Figure 6

Punicalagin promotes autophagy by increasing LC3-II level.

(A) NB4 and (B) MOLT-4 cells were treated with $\mathrm{IC}_{50}$ of punicalagin for $48 \mathrm{~h}$ and analyzed LC3-

II MFI using flow cytometry. (C) Quantitative result of LC3-II level. *p $<0.05$ was considered to be a statistically significant difference from the control group. 
A
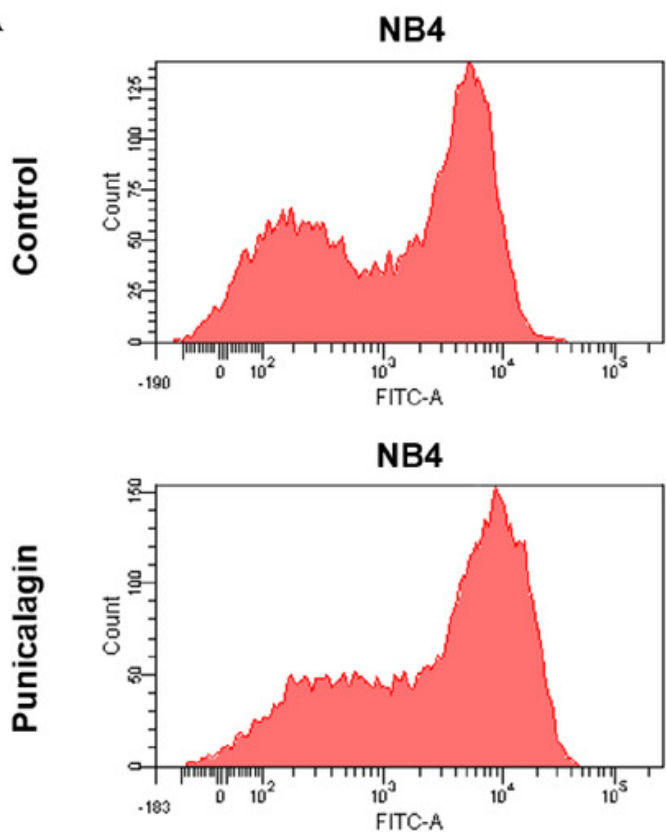

C

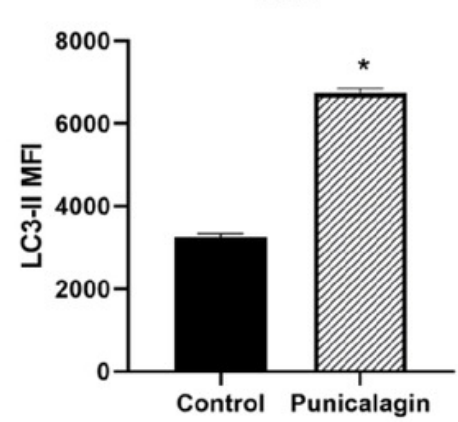

B

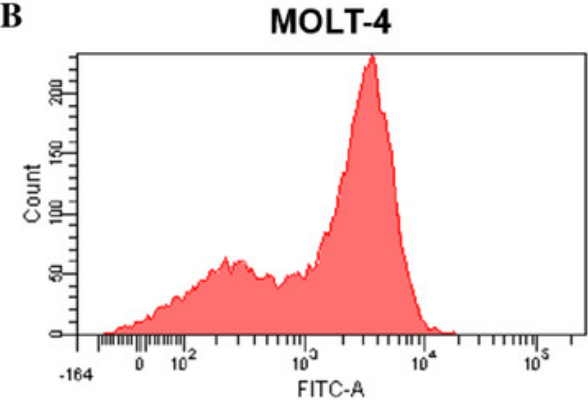

MOLT-4

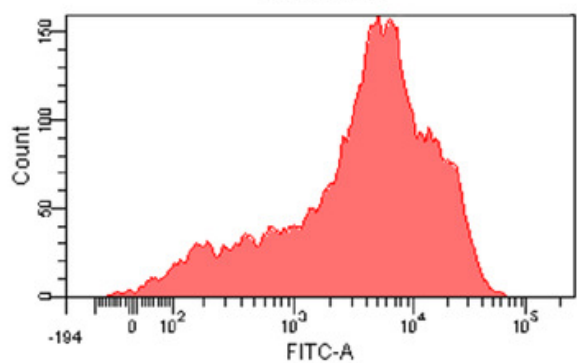

MOLT-4

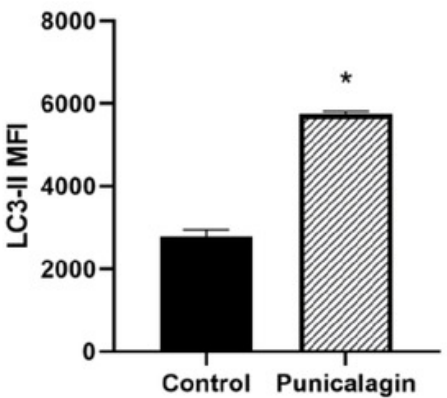




\section{Figure 7}

Effect of punicalagin on mRNA expression of apoptotic and autophagic genes.

Leukemic cells were treated with $\mathrm{IC}_{50}$ of punicalagin for $48 \mathrm{~h}$. The mRNA expression of (A)

caspase family genes, (B) Bcl-2 family as well as (C) ULK1 and mTOR were determined using reverse transcription-quantitative PCR. ${ }^{*} p<0.05$ was considered to be a statistically significant difference from the control group. 

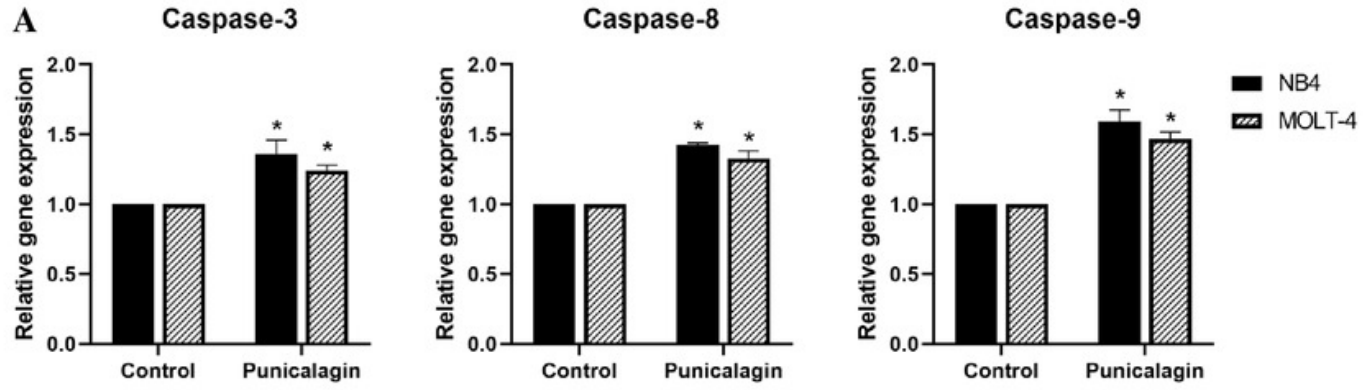

B

Bax

Bcl-2
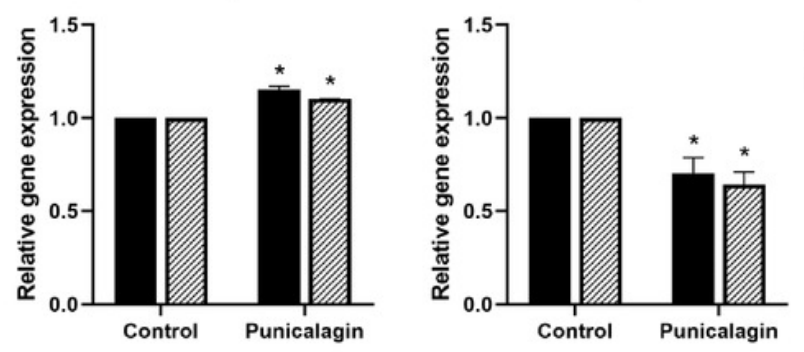

C

ULK1

mTOR
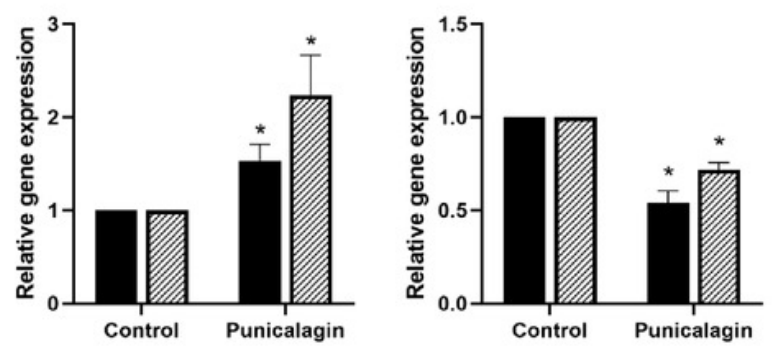

- NB4

m MOLT-4

moLT-4 


\section{Figure 8}

Construction of protein-chemical interaction using STITCH.

Interactions between protein and chemicals are represented by green lines while proteinprotein interactions are represented by grey lines. Stronger associations are shown by thicker lines. CASP3, caspase- 3; CASP8, caspase-8; CASP9, caspase-9; BAX, BCL2-associated $X$ protein; BCL2, B-cell CLL/lymphoma; MTOR, mechanistic target of rapamycin; ULK1, unc-51-like kinase 1; PTGS2, prostaglandin-endoperoxide synthase 2 or cyclooxygenase 2; TLR4, toll-like receptor 4; RPTOR, regulatory associated protein of MTOR; RICTOR, RPTOR independent companion of MTOR; RPS6KB1, ribosomal protein 56 kinase; MLST8, MTOR associated protein; AKT1, v-akt murine thymoma viral oncogene homolog; EIF4EBP1, eukaryotic translation initiation factor $4 \mathrm{E}$ binding protein 1; FKBP1A, FK506 binding protein 1A; MAPKAP1, mitogen-activated protein kinase associated protein 1; APAF1, apoptotic protease activating factor 1; BCL2L11, BCL2-like 11 


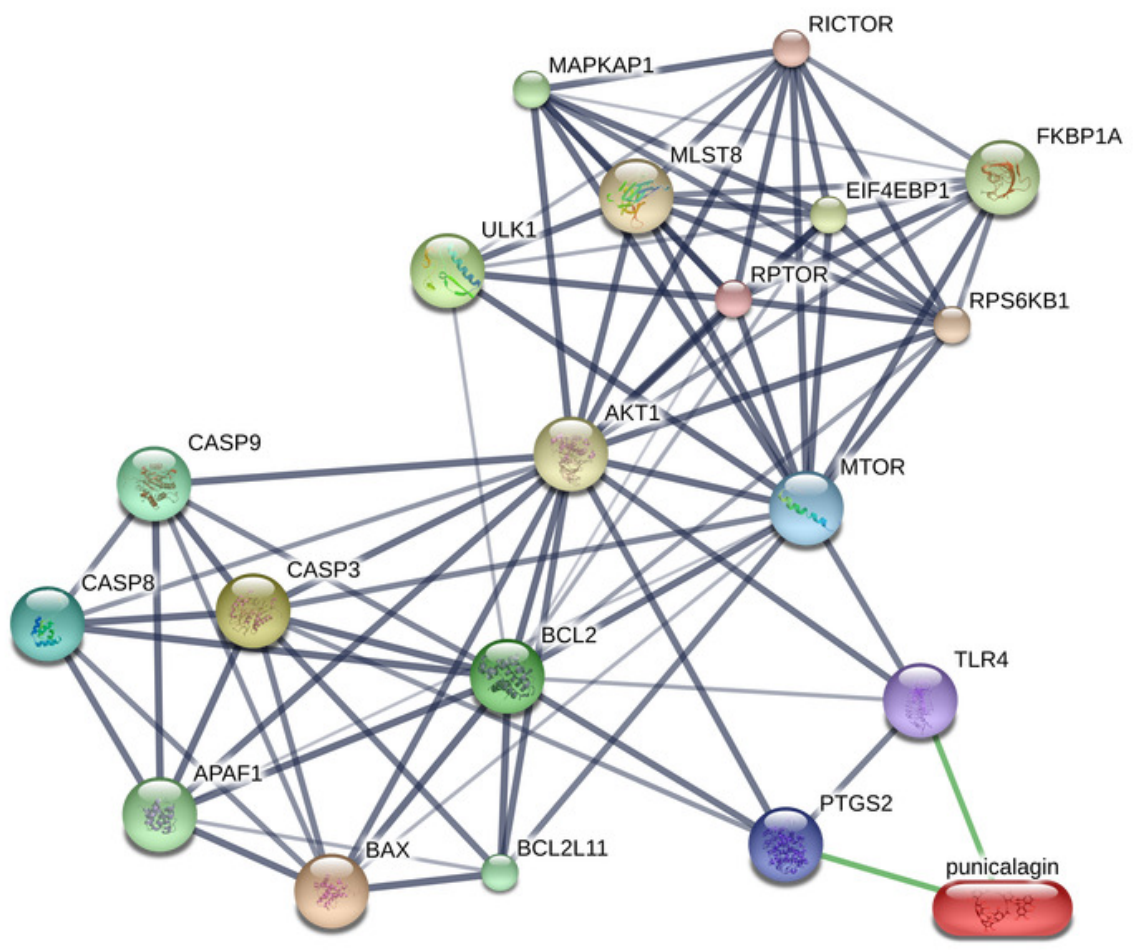




\section{Table 1 (on next page)}

The sequence of primers used in this study. 
1 Table 1: The sequence of primers used in this study.

\begin{tabular}{|c|c|}
\hline Primers & Sequence \\
\hline \multirow{2}{*}{ Caspase-3 } & F: 5'-TTCAGAGGGGATCGTTGTAGAAGTC-3' \\
\hline & R: 5'-CAAGCTTGTCGGCATACTGTTTCAG-3' \\
\hline \multirow{2}{*}{ Caspase- 8} & F: 5'-GATCAAGCCCCACGATGAC-3' \\
\hline & R: 5'-CCTGTCCATCAGTGCCATAG-3' \\
\hline \multirow{2}{*}{ Caspase-9 } & F: 5'-CATTTCATGGTGGAGGTGAAG-3' \\
\hline & R: 5'-GGGAACTGCAGGTGGCTG-3' \\
\hline \multirow{2}{*}{ Bax } & F: 5'-CGAGAGGTCTTTTTCCGAGTG-3' \\
\hline & R: 5'-GTGGGCGTCCCAAAGTAGG-3' \\
\hline \multirow{2}{*}{$\mathrm{Bcl}-2$} & F: 5'-ATGTGTGTGGAGAGCGTCAA-3' \\
\hline & R: 5'-GCCGTACAGTTCCACAAAGG-3' \\
\hline \multirow{2}{*}{ mTOR } & F: 5'-CGCTGTCATCCCTTTATCG-3' \\
\hline & R: 5'-ATGCTCAAACACCTCCACC-3' \\
\hline \multirow{2}{*}{ ULK1 } & F: 5-'GGCAAGTTCGAGTTCTCCCG-3' \\
\hline & R: 5'-CGACCTCCAAATCGTGCTTCT-3' \\
\hline \multirow{2}{*}{ GAPDH } & F: 5'-GCACCGTCAAGGCTGAGAA-3' \\
\hline & R: 5'-AGGTCCACCACTGACACGTTG-3' \\
\hline
\end{tabular}

2 
Table 2 (on next page)

Comparative statistics of viability between punicalagin-treated cells and control cells. 
1 Table 2: Comparative statistics of viability between punicalagin-treated cells and control

2 cells.

\begin{tabular}{|c|c|c|c|c|c|c|c|}
\hline \multicolumn{8}{|c|}{$24 \mathrm{~h}$} \\
\hline \multicolumn{2}{|c|}{ Group } & $\begin{array}{c}\text { \%Cell viability } \\
\text { of NB4 } \\
(\text { mean } \pm \text { S.E.M) }\end{array}$ & p-value & \multicolumn{2}{|c|}{ Group } & $\begin{array}{c}\text { \%Cell viability } \\
\text { of MOLT-4 } \\
(\text { mean } \pm \text { S.E.M) }\end{array}$ & p-value \\
\hline \multicolumn{2}{|l|}{ Control } & $100.00 \pm 0.00$ & - & \multicolumn{2}{|l|}{ Control } & $100.00 \pm 0.00$ & - \\
\hline \multirow{4}{*}{$\begin{array}{l}\text { Punicalagin } \\
\quad(\mu \mathrm{g} / \mathrm{ml})\end{array}$} & 25 & $77.50 \pm 1.26$ & 0.2190 & \multirow{4}{*}{$\begin{array}{l}\text { Punicalagin } \\
\quad(\mu \mathrm{g} / \mathrm{ml})\end{array}$} & 25 & $86.42 \pm 3.22$ & 0.3743 \\
\hline & 50 & $54.13 \pm 2.39$ & 0.0058 & & 50 & $73.17 \pm 8.22$ & 0.0238 \\
\hline & 75 & $31.02 \pm 8.81$ & 0.0003 & & 75 & $40.83 \pm 6.99$ & 0.00007 \\
\hline & 100 & $17.37 \pm 2.21$ & 0.00005 & & 100 & $16.53 \pm 0.56$ & 0.000003 \\
\hline \multicolumn{8}{|c|}{$48 \mathrm{~h}$} \\
\hline \multicolumn{2}{|c|}{ Group } & $\begin{array}{c}\text { \%Cell viability } \\
\text { of NB4 } \\
(\text { mean } \pm \text { S.E.M) }\end{array}$ & p-value & \multicolumn{2}{|c|}{ Group } & $\begin{array}{c}\text { \%Cell viability } \\
\text { of MOLT-4 } \\
(\text { mean } \pm \text { S.E.M) }\end{array}$ & p-value \\
\hline \multicolumn{2}{|l|}{ Control } & $100.00 \pm 0.00$ & - & \multicolumn{2}{|l|}{ Control } & $100.00 \pm 0.00$ & - \\
\hline \multirow{4}{*}{$\begin{array}{l}\text { Punicalagin } \\
(\mu \mathrm{g} / \mathrm{ml})\end{array}$} & 25 & $79.06 \pm 1.26$ & 0.1234 & \multirow{4}{*}{$\begin{array}{c}\text { Punicalagin } \\
(\mu \mathrm{g} / \mathrm{ml})\end{array}$} & 25 & $78.66 \pm 1.92$ & 0.0175 \\
\hline & 50 & $48.07 \pm 8.85$ & 0.0004 & & 50 & $61.56 \pm 5.81$ & 0.0002 \\
\hline & 75 & $30.62 \pm 7.91$ & 0.00003 & & 75 & $34.29 \pm 5.65$ & 0.0000019 \\
\hline & 100 & $8.65 \pm 2.78$ & 0.000003 & & 100 & $14.17 \pm 1.68$ & 0.0000002 \\
\hline
\end{tabular}

3

i Significantly different for $\mathrm{p}$-values $<0.05$ are in bold 
Table 3(on next page)

Statistical analysis of cell viability between daunorubicin-treated leukemic cells and control cells. 
1 Table 3: Statistical analysis of cell viability between daunorubicin-treated leukemic cells

2 and control cells.

\begin{tabular}{|c|c|c|c|c|c|c|c|}
\hline \multicolumn{8}{|c|}{$24 \mathrm{~h}$} \\
\hline \multicolumn{2}{|c|}{ Group } & $\begin{array}{c}\text { \%Cell viability } \\
\text { of NB4 } \\
(\text { mean } \pm \text { S.E.M) }\end{array}$ & p-value & \multicolumn{2}{|c|}{ Group } & $\begin{array}{c}\text { \%Cell viability } \\
\text { of MOLT-4 } \\
\text { (mean } \pm \text { S.E.M) }\end{array}$ & p-value \\
\hline \multicolumn{2}{|c|}{ Control } & $100.00 \pm 0.00$ & - & \multicolumn{2}{|c|}{ Control } & $100.00 \pm 0.00$ & - \\
\hline \multirow{4}{*}{ 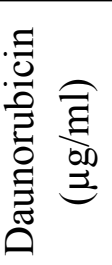 } & 0.25 & $77.31 \pm 5.55$ & 0.0095 & \multirow{4}{*}{ 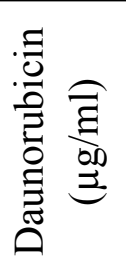 } & 0.25 & $84.85 \pm 1.35$ & 0.021 \\
\hline & 0.5 & $47.99 \pm 5.58$ & 0.0000121 & & 0.5 & $53.14 \pm 1.61$ & 0.0000025 \\
\hline & 0.75 & $33.27 \pm 1.21$ & 0.0000012 & & 0.75 & $40.79 \pm 4.74$ & 0.0000003 \\
\hline & 1.0 & $30.60 \pm 0.93$ & 0.0000008 & & 1.0 & $32.40 \pm 3.45$ & 0.0000001 \\
\hline \multicolumn{8}{|c|}{$48 \mathrm{~h}$} \\
\hline \multicolumn{2}{|c|}{ Group } & $\begin{array}{c}\text { \%Cell viability } \\
\text { of NB4 } \\
\text { (mean } \pm \text { S.E.M) }\end{array}$ & p-value & \multicolumn{2}{|c|}{ Group } & $\begin{array}{c}\text { \%Cell viability } \\
\text { of MOLT-4 } \\
\text { (mean } \pm \text { S.E.M) }\end{array}$ & p-value \\
\hline \multicolumn{2}{|c|}{ Control } & $100.00 \pm 0.00$ & - & \multicolumn{2}{|c|}{ Control } & $100.00 \pm 0.00$ & - \\
\hline \multirow{4}{*}{ 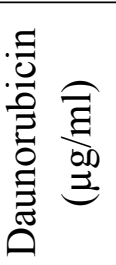 } & 0.25 & $52.61 \pm 6.92$ & 0.0001 & \multirow{4}{*}{ 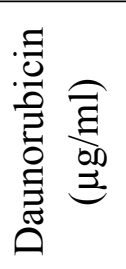 } & 0.25 & $61.04 \pm 3.57$ & 0.0000876 \\
\hline & 0.5 & $22.35 \pm 6.57$ & 0.0000012 & & 0.5 & $22.37 \pm 6.53$ & 0.0000001 \\
\hline & 0.75 & $15.94 \pm 0.44$ & 0.0000006 & & 0.75 & $15.99 \pm 1.53$ & 0.0000001 \\
\hline & 1.0 & $14.75 \pm 0.06$ & 0.0000005 & & 1.0 & $14.27 \pm 1.13$ & 0.0000001 \\
\hline
\end{tabular}

3

$4 \mathrm{i}$

i Significantly different for $\mathrm{p}$-values $<0.05$ are in bold 


\section{Table 4 (on next page)}

The comparative statistical analyses ( $p$-value) of the combination results. 
1 Table 4: Comparative statistics of the combination result.

\begin{tabular}{|c|c|c|c|c|c|}
\hline \multirow[b]{2}{*}{ Cell } & \multirow[b]{2}{*}{ Group } & \multicolumn{2}{|l|}{$24 \mathrm{~h}$} & \multicolumn{2}{|l|}{$48 \mathrm{~h}$} \\
\hline & & $\begin{array}{l}\% \text { Cell viability } \\
(\text { mean } \pm \text { S.E.M) }\end{array}$ & p-value & $\begin{array}{l}\text { \% Cell viability } \\
(\text { mean } \pm \text { S.E.M) }\end{array}$ & p-value \\
\hline \multirow{4}{*}{ NB4 } & The combination ${ }^{1}$ & $29.66 \pm 2.605$ & \multirow{2}{*}{0.028} & $20.26 \pm 0.358$ & \multirow{2}{*}{0.044} \\
\hline & Punicalagin $\left(\mathrm{IC}_{50}\right)$ & $56.01 \pm 7.332$ & & $52.78 \pm 7.044$ & \\
\hline & The combination $^{1}$ & $29.66 \pm 2.605$ & \multirow{2}{*}{0.044} & $20.26 \pm 0.358$ & \multirow{2}{*}{0.011} \\
\hline & Daunorubicin $\left(\mathrm{IC}_{50}\right)$ & $48.33 \pm 5.885$ & & $52.69 \pm 3.458$ & \\
\hline \multirow{4}{*}{ MOLT-4 } & The combination ${ }^{1}$ & $30.67 \pm 3.995$ & \multirow{2}{*}{0.039} & $25.51 \pm 2.786$ & \multirow{2}{*}{0.008} \\
\hline & Punicalagin $\left(\mathrm{IC}_{50}\right)$ & $54.28 \pm 6.744$ & & $58.59 \pm 6.038$ & \\
\hline & The combination $^{1}$ & $30.67 \pm 3.995$ & \multirow{2}{*}{0.009} & $25.51 \pm 2.786$ & \multirow{2}{*}{0.002} \\
\hline & Daunorubicin $\left(\mathrm{IC}_{50}\right)$ & $53.18 \pm 2.488$ & & $54.30 \pm 2.607$ & \\
\hline \multirow{4}{*}{ PBMC } & The combination $^{1}$ & $63.43 \pm 2.149$ & \multirow{2}{*}{0.002} & $67.53 \pm 4.966$ & \multirow{2}{*}{0.016} \\
\hline & Punicalagin $\left(\mathrm{IC}_{50}\right)$ & $85.24 \pm 2.306$ & & $90.25 \pm 2.742$ & \\
\hline & The combination $^{1}$ & $63.43 \pm 2.149$ & \multirow{2}{*}{0.032} & $67.53 \pm 4.966$ & \multirow{2}{*}{0.045} \\
\hline & Daunorubicin $\left(\mathrm{IC}_{50}\right)$ & $83.59 \pm 5.868$ & & $88.74 \pm 5.476$ & \\
\hline PBMC & \multirow{2}{*}{ The combination ${ }^{1}$} & $63.43 \pm 2.149$ & \multirow{2}{*}{0.001} & $67.53 \pm 4.966$ & \multirow{2}{*}{0.001} \\
\hline NB4 & & $29.66 \pm 2.605$ & & $20.26 \pm 0.358$ & \\
\hline PBMC & \multirow{2}{*}{ The combination ${ }^{1}$} & $63.43 \pm 2.149$ & \multirow{2}{*}{0.002} & $67.53 \pm 4.966$ & \multirow{2}{*}{0.002} \\
\hline MOLT-4 & & $30.67 \pm 3.995$ & & $25.51 \pm 2.786$ & \\
\hline
\end{tabular}

2

${ }^{1}$ The combination containing $\mathrm{IC}_{50}$ of punicalagin and $\mathrm{IC}_{50}$ of daunorubicin

2 Significantly different for $\mathrm{p}$-values $<0.05$ are in bold 